\title{
Experimental Investigation on Hip Implant Materials Development through Analytical and Finite Element Analysis: 3D Modelled Compuited Tomography
}

\author{
ShaileshPimpale $^{1, * \text { (D) }}$, Manish Deshmukh ${ }^{2}$, Rajesh Shelke ${ }^{3}$, Dheeraj Deshmukh ${ }^{4}$ \\ 1 Department of Mechanical Engineering, JSPM'S Rajarshi Shahu College of Engineering, Pune- Maharashtra, India; \\ shailesh_pimpale@ rediffmail.com (S.P.); \\ 2 Department of Mechanical Engineering, AISSMS College of Engineering, Pune-Maharashtra, India; \\ msdeshmukh@aissmscoe.com (M.D.); \\ 3 Mediteknosys, Pune-Maharashtra, India; rajeshshelke21@gmail.com (R.S.); \\ 4 Department of Mechanical Engineering, G. H. Raisoni College of Engineering, Nagpur- Maharashtra, India; \\ deshmukh.dheeraj@gmail.com (D.D.); \\ * Correspondence: shailesh_pimpale@rediffmail.com (S.P.);
}

Received: 24.05.2021; Revised: 1.07.2021; Accepted: 5.07.2021; Published: 13.07.2021

\begin{abstract}
Biomechanics is the interdisciplinary area comprising biomedical and mechanical domain, continuations in research of alternative and sustainable materials, which refers to the mechanical examine. This current work focuses on hip implant material development through analytical and finite element analysis. The femur bone head is 3D modeled through computed tomography (CT) images extracted data and modeled in SOLIDWORKS. The analytical analysis is performed on the femur head through Hertzian theory. The finite element analysis (FEA) (static structural analysis) is carried out in the ANSYS 19.2. The materials considered for the FEA are NbTiZrMo alloy, PEEK and CFR-PEEK for the hip implant. The analytical analysis is performed for eight different human routine activities, and the highest peak stress value is obtained for walking fast. The peak stress values obtained in FEA for CFR-PEEK material implant are lower than the maximum peak stress obtained by analytical analysis. The stress value obtained for CFR-PEEK material is somewhat higher than PEEK, but the contact pressure for PEEK material is way higher than CFR-PEEK material implant. So, it is concluded that the CFR-PEEK material is the ideal alternative as compared to other materials.
\end{abstract}

Keywords: Hertziantheory; femur head; static analysis; finite element analysis.

(C) 2021 by the authors. This article is an open-access article distributed under the terms and conditions of the Creative Commons Attribution (CC BY) license (https://creativecommons.org/licenses/by/4.0/).

\section{Introduction}

Biomechanical research is a continuous assessment and search of a solution to biological problems through integrating the biomedical and mechanical research areas. The biomechanical researchers globally focus the hip implant development with respective the novel material deployment. This study evaluates the stress distribution on the femur bone head during different activities through an analytical method. Finite element analysis is being carried for the femur head with respective different materials, and the stress distribution and contact pressure values are evaluated and compared with the results of the analytical analysis results. An extensive literature survey is also carried out before performing the analyses. The human hip natural femur bone and the artificial implant are shown in Figure 1. 


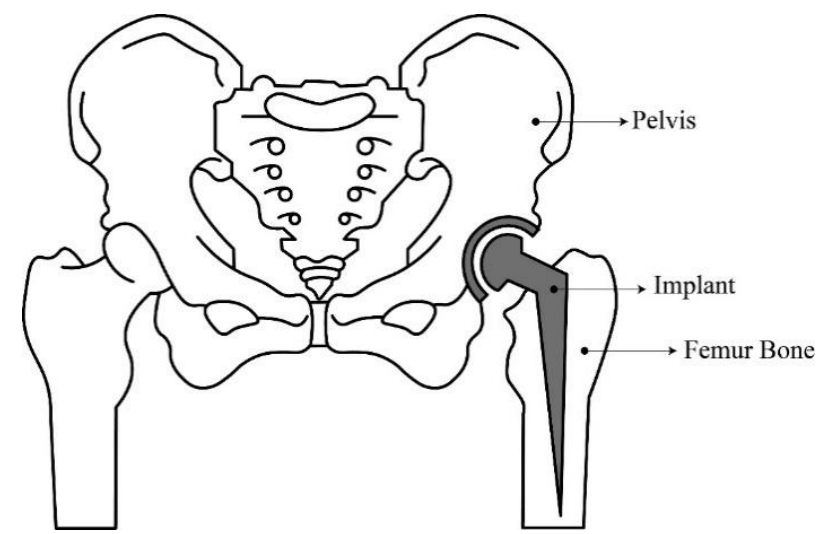

Figure 1. Human hip natural femur bone and the artificial implant.

Researchers have performed finite element analysis of the femur bone with respective contact forces and stress distribution in a study. The modeling of the femur bone is modeled in Solid Edge V19, and the stress analysis is performed in ANSYS 14.0. The stress analysis of femur bone at the hip joint is performed for the activities like a normal walking, standing, running, and jumping. The outcomes were compared with the last studies, and it is discovered that the outcomes found in FEA are optimized as compared to the previous studies [1-3]. A. E. Yousif et al. have performed finite element analysis of the femur bone, which is modeled through computer tomography (CT) images. The gait analysis is also performed and compared with previous studies. The normal stresses and forces were analyzed for the normal walking and standing with respect to a single cycle. The results were found to be beneficial to the orthopedic surgeon in the case of hip joint arthroplasty and in studies of hip joint implants [4]. Researchers have carried out finite element analysis and computational modeling of the forces acting on the femur neck during acetabular fractures. Due to the medical condition of the femur bone in osteoporosis of elderly patients, it becomes necessary to study the load-bearing capacity of the acetabulum and femoral head. Studies have been performed to evaluate femur bone articulation under such conditions to reduce the chances of femoral neck fractures. It is examined through finite element analyses. The finite model of the femoral neck is created through the computed tomography (CT) images, and point load is applied on the acetabulum. The point loads have differed at the tip of the femur head, and the deformation and stress levels were observed at the neck region. It is discovered that the stress is increased with the movement of the point load from the center. It is also found that the bending moment in the medial neck shaft is increased with the differing position of the point load. It was eventually concluded that patients with a medical condition like osteoporosis have a higher risk of femur neck failure [59].

Researchers have developed a ceramic and metal composite comprising aluminum oxide and niobium reinforced with silicon carbide nanoparticles for studying its possible applications as a femoral head implant in the case of total hip arthroplasty. The samples of the composites were produced through the hot pressing of powders at $1425{ }^{\circ} \mathrm{C}$ and under $35 \mathrm{MPa}$ pressure, which is further tested through electron microscopy and mechanical testing under several circumstances. It was discovered that the flexural strength and interfacial shear strength of aluminum oxide niobium silicon carbide composite laminate were highest compared to other laminates. It was concluded that the aluminum oxide niobium silicon carbide composite comprises higher beneficial characteristics in the case of femur head applications as compared to aluminum oxide and others [10-19]. In a study, researchers have developed a method to produce the zirconia-toughened alumina (ZTA) for applying it as a femur head implant through 
compression molding and sintering. It was discovered that the produced implant comprises exceptional properties, such as a smoother surface and more prominent geometrical compliance. The relation of the microstructure produced to the producing method was described by utilizing micro-computed tomography. The mechanical strength was examined through the burst strength measurements technique. In order to verify or examine the biocompatibility of the produced implant femur head, the in vitro cell culture examination was performed [20-26]. The bearing surface wear in the hip implant in total hip arthroplasty is the most critical reason for the failure and can cause osteolysis. Researchers have examined the zirconia toughened alumina in a study, and the oxide-coated zirconium niobium femoral head was examined and compared with the cobalt-chromium femoral head. The wear abrasion study was carried out, and the results were compared with the cobalt-chromium femur head. The effect of ceramic on metal is also tested in this study. It is discovered that the zirconia toughened alumina and oxide-coated zirconium niobium femoral head has higher wear resistance as compared to cobalt-chromium femur implant [27-38].

\subsection{Arthroplasty and hemiarthroplasty.}

In the case of the total hip joint replacement, it comprises the removal and replacement of the discredited joint with a part made through any other biocompatible material (metal, plastic or ceramic) which is known as prosthesis. The prosthesis design is critical as it involves replicating the motion and movement of the joint in compatible mode [39-43]. Two primary types of hip transplants are classified based on the transplant containing acetabulum of biomaterial and acetabulum of the patient's natural bone. The biomaterial acetabulum presence is known as arthroplasty, and absence is known as hemiarthroplasty. The difference between arthroplasty and hemiarthroplasty can be seen the Figure 2 .

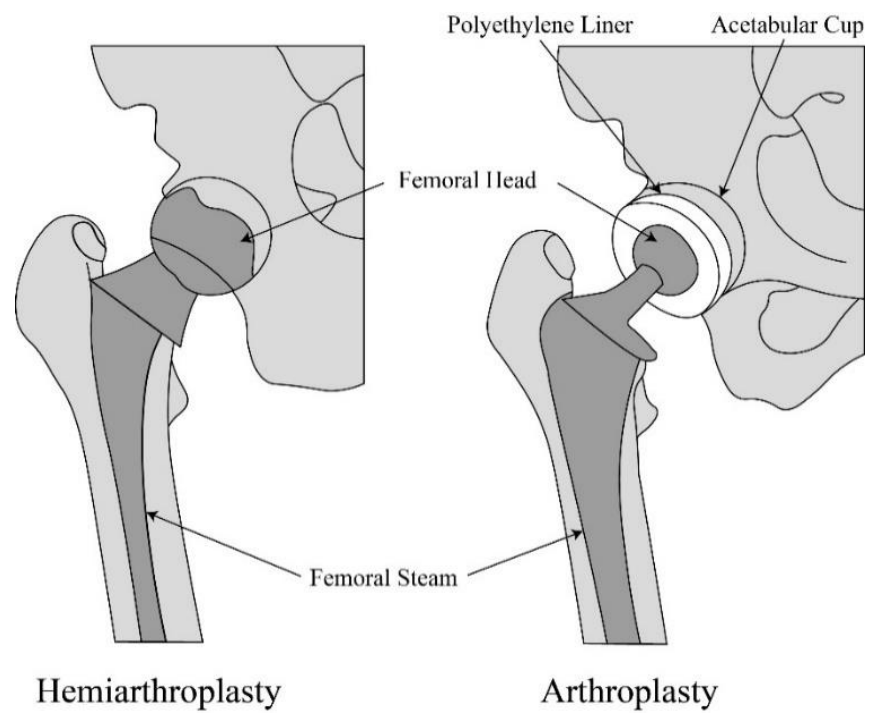

Figure 2. Arthroplasty and hemiarthroplasty.

Hemiarthroplasty is a surgical operation that replaces half of a joint with an artificial replacement and leaves the other part in its natural state[44-50].

With benefits like decreased surgical and recovery time, hemiarthroplasty is preferred, along with the preservation of more natural tissue than total arthroplasties.

Despite all these benefits, one of the main shortcomings of the surgery mentioned above is that they cause accelerated damage to the natural or native cartilage that they articulate 
against. These surgeries are prevalent in the elderly population, which is above age 60 due to osteoarthritis. Thus, making osteoarthritis the main cause of joint replacement surgeries. The main problem of hip hemiarthroplasty is due to acetabular damage, which is natural tissue. This mismatch of shape will always exist between the anatomy and implants. This will lead to implant loosening leading to the most common complications of hemiarthroplasties. 3D printing and rapid manufacturing of patient-specific implants are possible, which can mitigate the shape effect.

\section{Materials and Methods}

\subsection{Material selection.}

Material selection for orthopedic implants, especially for hip implants, is a complex integrated task due to the involvement of multiple dependent parameters. The hemiarthroplasty is usually known as total arthroplasty, which comprises the utilization of the natural tissue, but is heavily affected by the rise in wear with respect to time [44]. The selection criteria depend on various aspects like chemical, biological, physical, economic, and mechanical aspects, resulting in cost-optimized and better-performing material. The materials contact analysis is the prior interest, which defines the wear characteristics clearly. The materials usually studied for contact analysis with respect to hip implants are ceramic over polyethylene, metal over metal, ceramic over ceramic, and metal over polyethylene.

With new modern materials and manufacturing techniques, we will explore the possibility of new age hemiarthroplasty instead of a total arthroplasty. The hemiarthroplasty replaces the ball shape portion of the femur bone, while the acetabulum portion is kept as the natural bone. It is usually preferred as a total hip replacement but with this change. The hip bone's socket portion of an anatomy is kept intact while replacing the ball portion of the femoral bone in the hip joint. The selection of an optimal orthopedic material in all senses is a complex task [51-58].

Novel material development for implants while staying under manufacturing constraints is a challenging task. Various factors drive the material selection process, but they usually depend on major properties, biocompatibility, and economics. Usually, an orthopedic surgeon selects implants considering the patient's age, level of activity, and lifestyleactive/laidback. Metal on polymer (MoP)- This type of implant comprises major problems related to the wear rate of material, which eventually affects the joint anatomy in a lower period. Metal on metal (MoM)- These types of implants demonstrate less wear compared to MoP. Though it has the least amount of wear, the metallic ions released from this implant are highly toxic. Popular materials used are cobalt-chromium alloys to minimize the effect of metallic ions compared to stainless steel. Ceramic on polymer - Metallic ions can be reduced drastically with a ceramic femoral ball. Ceramic on ceramic- $\mathrm{CoC}$ has the lowest metallic ion release of among all prosthesis

NbTiZrMo alloy on bone- This material is the newest biomaterial lot with modulus closer to cortical bone among all metals and alloys.

Peek on bone- Now, with Peek, we are trying to articulate PEEK femoral bone on cartilage to achieve all benefits of hemiarthroplasty and mitigating the adverse effect. 


\subsection{Analytical process.}

The human anatomy comprises the femoral head (i.e., a convex sphere of smaller size) implanted or engrafted in the acetabulum (i.e., a concave hemisphere or cup of larger size). In this case, three coordinate systems are applied to describe the relation of the hip motion with resultant load, which are shown in Figure 3. There is an absolute coordinate system X, Y, and $\mathrm{Z}$, which is located at the center on the right side of the femoral head. In the absolute coordinate system, the facade plane is $\mathrm{XZ}$, the median-sidelong is $\mathrm{X}$-axis, and the backside-prior is $\mathrm{Y}$ axis. The second coordinate system is situated at the center of the cup Xc, Yc, and Zc, where the cup flat face plane is Xc-Yc, and the Xc and Yc axis are directed towards the forefront of the cup. The angle formed by the axis $X$ and $X c$, " $\beta$ " is the cup inclination angle. The angle formed by the axis $X$ and $Z c$, “ $\eta$ " is the cup anteversion angle. The resultant load vector $F(t)$ is applied on the point "P", which is situated on the articular surface. There is also a spherical coordinate system comprising $\rho, \theta$, and $\varphi$, which is situated on the articular surface axis Xc, Yc, and $\mathrm{Zc}$.

The anatomy presents that the femur head has a hemispherical shape and fluent surface with fresh state gristle. This reflects the surface with edge contact of the femoral head into the acetabulum, and the size depends on the resultant loading and stress distribution of the head with a cup. In this research, the Hertzian theory is deployed to account for the stress distribution, which is usually applied in contact with nonconforming geometrical shapes[59]. The complete calculations are given in the following section.

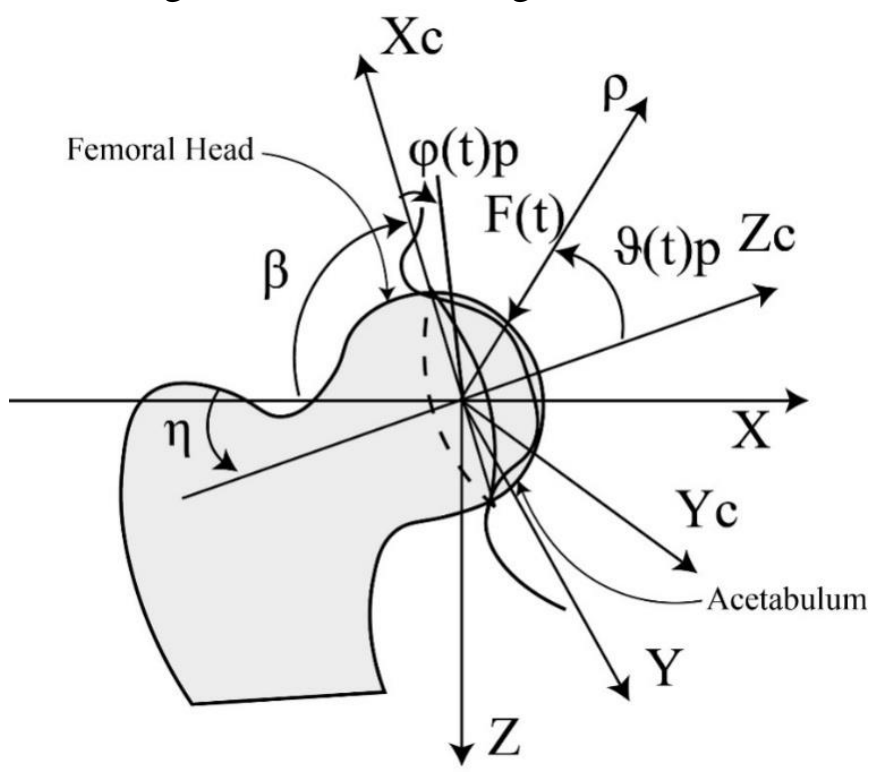

Figure 3. Coordinate system for the femur head in analytical analysis.

Let the components acting on the human hip be in $F_{x}(t), F_{y}(t)$ and $F_{z}(t)$ in $\mathrm{X}, \mathrm{Y}$, and $\mathrm{Z}$ directions, respectively, and the hip resultant load vector magnitude is:

$$
\mathrm{F}(\mathrm{t})=\sqrt{F_{x}^{2}(t)+F_{y}^{2}(t)+F_{z}^{2}(t)}
$$

The coordinates of the point of application " $P$ ", which are, $X_{p}(t), Y_{p}(t)$ and $Z_{p}(t)$ are accounted through:

$$
X_{p}(t)=\frac{D_{c}}{2} \cos \left[\tan ^{-1}\left(\frac{-F_{z}(t)}{\sqrt{F_{x}^{2}(t)+F_{y}^{2}(t)}}\right)\right] \sin \left[\tan ^{-1}\left(\frac{-F_{x}(t)}{-F_{y}(t)}\right)\right]
$$




$$
\begin{gathered}
Y(t)=\frac{D_{c}}{2} \cos \left[\tan ^{-1}\left(\frac{-F_{z}(t)}{\sqrt{F_{x}^{2}(t)+F_{y}^{2}(t)}}\right)\right] \cos \left[\tan ^{-1}\left(\frac{-F_{x}(t)}{-F_{y}(t)}\right)\right] \\
Z_{p}(t)=\frac{D_{c}}{2} \sin \left[\tan ^{-1}\left(\frac{-F_{z}(t)}{\sqrt{F_{x}^{2}(t)+F_{y}^{2}(t)}}\right)\right]
\end{gathered}
$$

where the Dc is the diameter of the cup articular surface. After transferring the coordinates of the point of application "P" to the cup's system, which are $X_{c}, Y_{c}$ and $Z_{c}$.

$$
\begin{gathered}
X_{c}=X \sin \eta+Y \cos \eta \\
Y_{c}=Z \sin \beta-(X \cos \eta-Y \sin \eta) \cos \beta \\
Z_{c}=Z \cos \beta+(X \cos \eta-Y \sin \eta) \sin \beta
\end{gathered}
$$

where the " $\eta$ " is cup anteversion angle and the " $\beta$ " is cup inclination angle, as shown in Figure. 3. Eventually, the spherical coordinates of the point of application "P", are evaluated in the following:

$$
\begin{gathered}
\rho=\frac{D_{c}}{2} \\
\theta=\cos ^{-1} \frac{2 Z_{c}}{D_{c}} \\
\varphi=\tan ^{-1} \frac{X_{c}}{Y_{c}}
\end{gathered}
$$

And further, the local contact stress can be calculated as follow:

$$
\sigma_{t}(\theta, \varphi)=\frac{3 F(t)}{2 \pi r^{2}(t)}\left[1-\frac{d_{t}^{2}(\theta, \varphi)}{r^{2}(t)}\right]^{\frac{1}{2}}
$$

where the $r(t)$ is the radius of the contact surface edge, which is evaluated through the equation as follows:

$$
r(t)=\left[\frac{3 \pi}{8} F(t)\left(\frac{1-V_{H}^{2}}{\pi E_{H}}-\frac{1-V_{C}^{2}}{\pi E_{C}}\right)\left(\frac{1}{D_{H}}-\frac{1}{D_{C}}\right)^{-1}\right]^{\frac{1}{3}}
$$

And the $d_{t}(\theta, \varphi)$ is the distance of the generic point of the contact surface from the axis of theload vector, which is evaluated through:

$$
d_{t}(\theta, \varphi)=\frac{D_{C}}{2} \sin \left\{\cos ^{-1}\left[\sin \theta \sin \theta_{P}(t) \cos \left(\varphi-\varphi_{P}(t)\right)+\cos \theta \cos \theta_{P}(t)\right]\right\}
$$

where, in equations (6) and (7), the $D_{H}$ is the femoral head diameter; the $E_{H}$ and the $E_{C}$ are Young's modulus for the hip and the cup, respectively; the $V_{H}$ and $V_{C}$ are the Poisson ratios for the hip and the cup, respectively.

Table 1. Parameters for the analytical analysis of the peak stress in the hip joint.

\begin{tabular}{l|l|l} 
Parameter & Value & Unit \\
\hline$P$ & 900 & $\mathrm{~N}$ (Newton) \\
\hline$\eta$ & 5 & ${ }^{\circ}$ (Degree) \\
\hline$\beta$ & 60 & ${ }^{\circ}$ (Degree) \\
\hline$D_{c}$ & 29.2 & mm (Millimeter) \\
\hline$D_{h}$ & 29 & $m m$ (Millimeter) \\
\hline$E_{c}$ & 1000 & MPa (Mega Pascal) \\
\hline$V_{c}$ & 0.5 & - \\
\hline$E_{h}$ & 210 & GPa (Giga Pascal) \\
\hline$V_{h}$ & 0.4 & -
\end{tabular}


The research article by Matej Daniel et al. has performed a collection of gait data of the eight dissimilar human routine activities with respect, which usually says high hip joint loads occur during daily routine activities [60]. The values considered for the peak stress evaluation in this study are given in Table 1 . The routine activities are represented in a detailed manner in Table 2.

Table 2. The detailed description of the routine activities considered in analytical analysis

\begin{tabular}{l|l|l|l} 
Activities & Speed & Level & Average speed $(\mathbf{m} / \mathbf{s})$ \\
\hline Slow walking & Slow speed & Ground-level & 0.98 \\
\hline Normal walking & Normal speed & Ground-level & 1.09 \\
\hline Fast walking & Fast speed & Ground-level & 1.46 \\
\hline Going upstairs & Walking up stair without any rail support (stair height $17 \mathrm{~cm})$ \\
\hline Going downstairs & Walking downstairs without any rail support (stair height $17 \mathrm{~cm})$ \\
\hline Standing up & $\begin{array}{l}\text { Standing up from a chair height of 50cm without the support and keeping both arms close to } \\
\text { the chest. }\end{array}$ \\
\hline Sitting down & $\begin{array}{l}\text { Sitting down to a chair height of 50cm without the support and keeping both arms close to the } \\
\text { chest. }\end{array}$ \\
\hline Knee bend & Up straight standing than bending knees and again standing up straight.
\end{tabular}

\section{Results and Discussion}

\subsection{Analytical method.}

The peak stress distributions for the hip joint are evaluated by utilizing the Hertzian theory for different human routine activities. The maximum peak stress values obtained for slowly walking activity is $11.2 \mathrm{MPa}$, walking normal activity is $11.4 \mathrm{MPa}$, and fast walking activity is $11.9 \mathrm{MPa}$. The maximum peak stress values obtained for bending knee activity is 10.2 $\mathrm{MPa}$, going up stair activity is $11.6 \mathrm{MPa}$, and going downstairs activity is $11.3 \mathrm{MPa}$. The maximum peak stress values obtained for standing up activity and sitting down activity is 10.3 MPa.

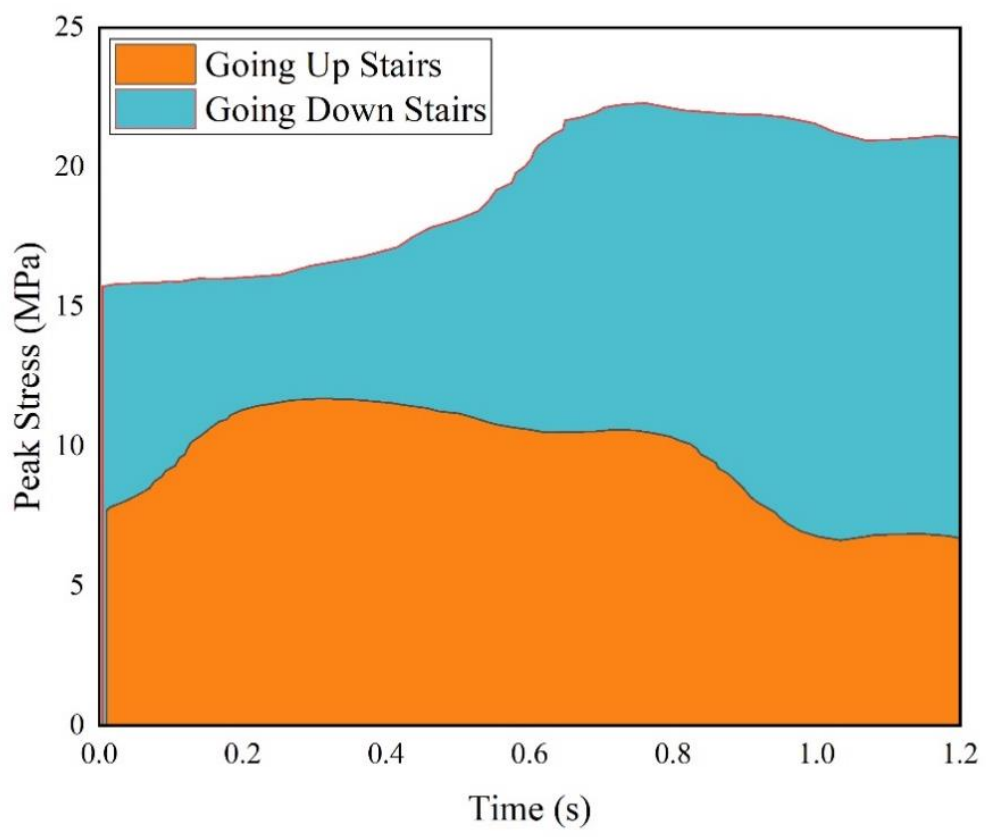

Figure 4. Peak stress stacked area graph of the going up and down stairs activities.

Higher peak stress values are accounted for in the fast walking activity, whereas the lowest is in the sitting down activity. The peak stress values obtained are more eminent in walking than other activities and relatively much higher in walking fast activity due to higher 
inertia forces. The minimum peak stress values obtained for slowly walking activity is $5.3 \mathrm{MPa}$, walking normal activity is $5.7 \mathrm{MPa}$ and walking fast activity is $6.6 \mathrm{MPa}$. The minimum peak stress values obtained for bending knee activity is $7.4 \mathrm{MPa}$, going up stair activity is $5.9 \mathrm{MPa}$ and going downstairs activity is $6.4 \mathrm{MPa}$. The minimum peak stress values obtained for standing up activity are $6 \mathrm{MPa}$, and sitting down is $5.5 \mathrm{MPa}$. The mean peak stress values obtained for slowly walking activity is $8.7 \mathrm{MPa}$, walking normal activity is $9.9 \mathrm{MPa}$ and walking fast activity is $9.6 \mathrm{MPa}$. The mean peak stress values obtained for bending knee activity is $8.7 \mathrm{MPa}$, going up stair activity is $8.9 \mathrm{MPa}$ and going downstairs activity is $9.2 \mathrm{MPa}$. The mean peak stress values obtained for standing up activity is $8.8 \mathrm{MPa}$, and sitting down activity is $7.7 \mathrm{MPa}$.

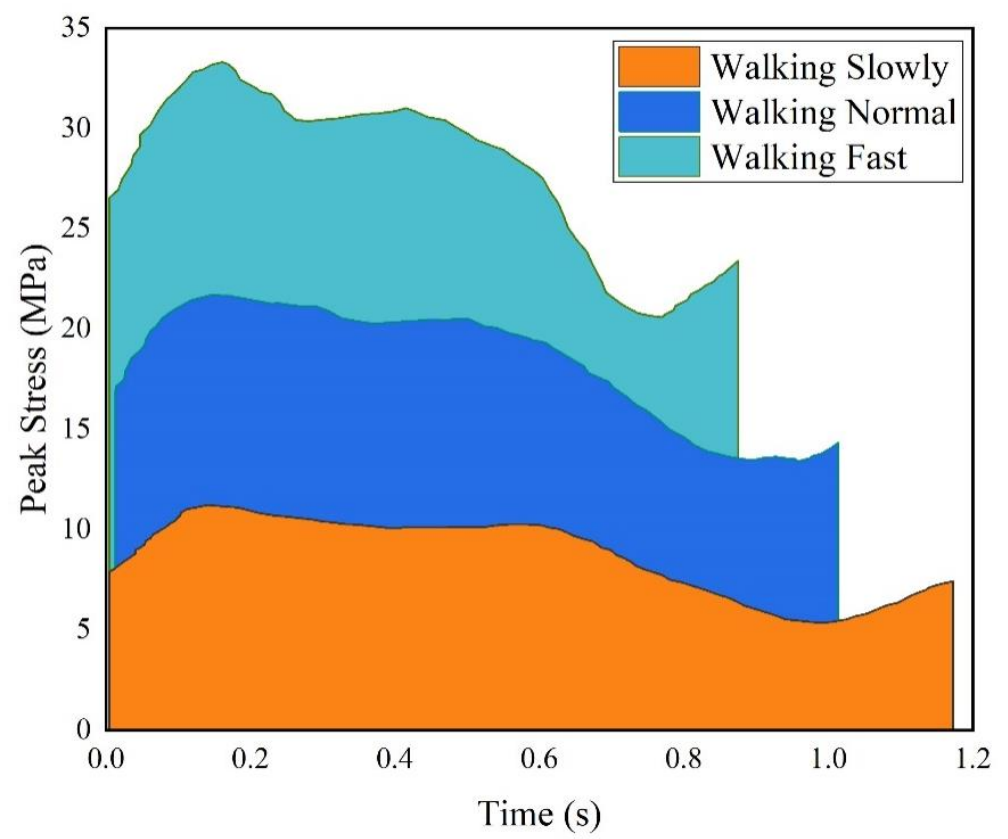

Figure 5. Peak stress stacked area graph of the walking slowly, normal and fast activities.

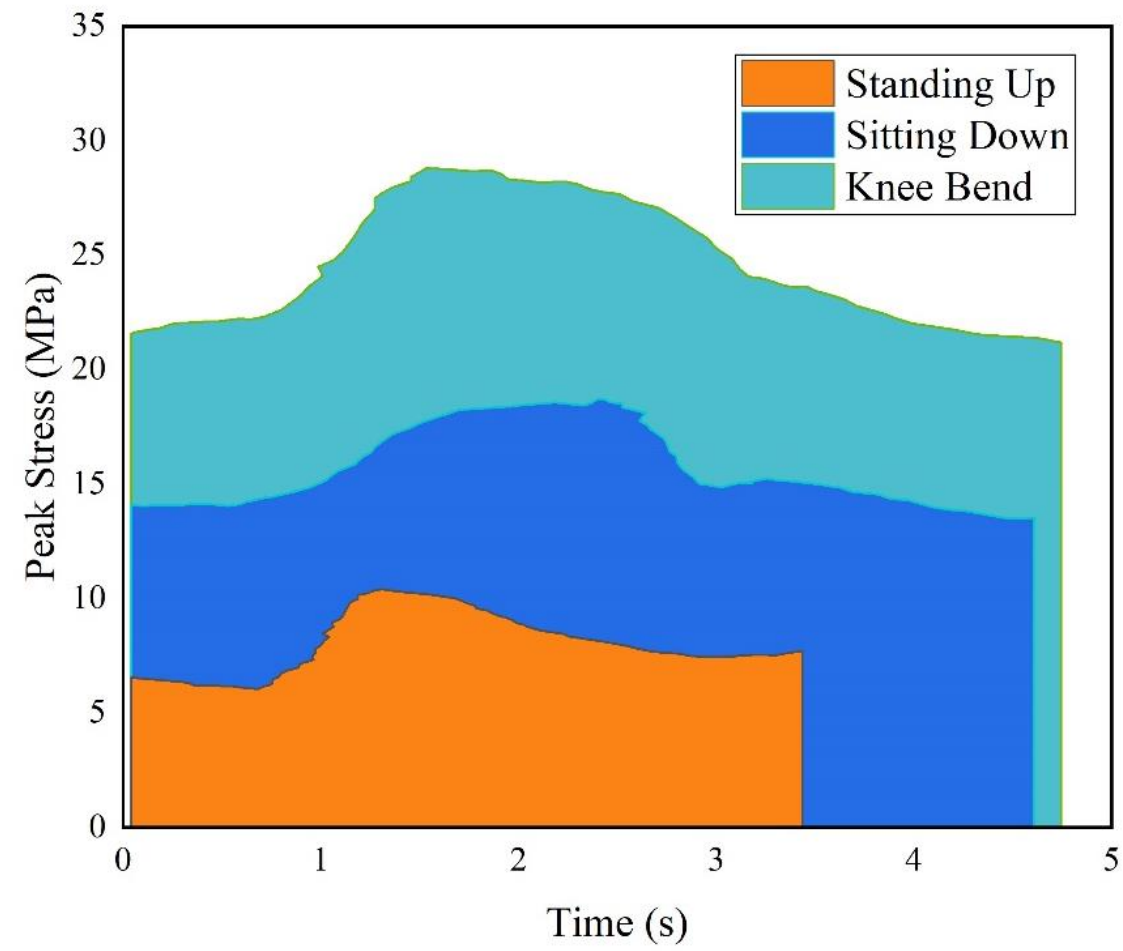

Figure 6. Peak stress stacked area graph of the standing up, sitting down, and knee bend activities. 
The maximum peak stress values range from $10.3 \mathrm{MPa}$ to $11.9 \mathrm{MPa}$, the minimum peak stress values range from 5.3 $\mathrm{MPa}$ to $7.4 \mathrm{MPa}$, and the mean peak stress values range from 7.7 $\mathrm{MPa}$ to $9.9 \mathrm{MPa}$. The factors causing the increase in the peak stress are the prominent body weight, the smaller diameter of the femoral head, smaller acetabular surface area, the closeness of the load to the acetabular rim, and compound collection of these factors.

The higher peak stress obtained in the fast walking activity is due to the higher contact forces and inertia forces. The peak stress stacked area graph for going upstairs and downstairs activities is shown in Figure 4. The peak stress stacked area graph for walking slowly, normal and fast activities is shown in Figure 5. The peak stress stacked area graph for standing up, sitting down, and knee bend activities is shown in Figure 6. The maximum, minimum, and mean peak stress values for all activities are shown in Figure 7.

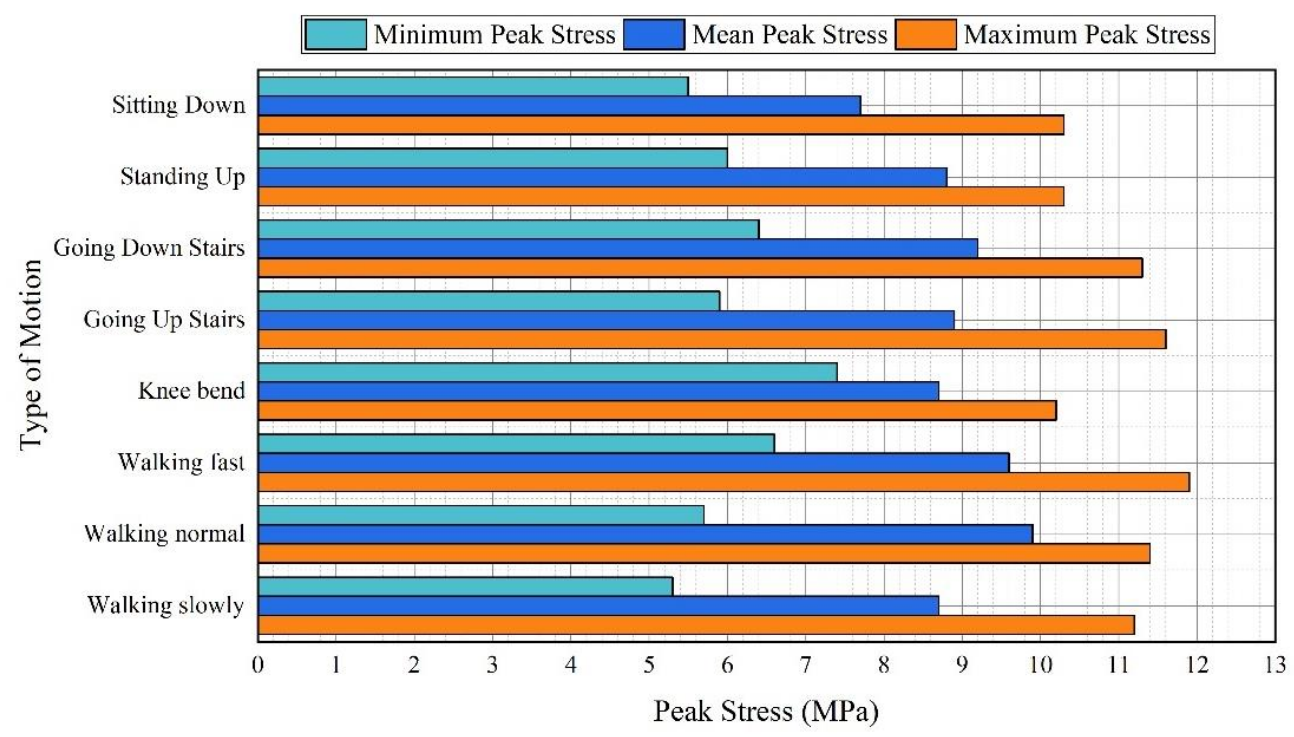

Figure 7. Maximum, minimum, and mean peak stress values for all activities.

\subsection{Materials of interest.}

The materials considered for the hip implant in this study are the NbTiZrMo alloy, PEEK, and CFR-PEEK; their properties are shown in Table 3. The whole idea in hemiarthroplasty is to use implant material with low stiffness to avoid stress shielding. The elastic modulus of Nb35Ti25Zr5Mo (Annealed) is $13 \mathrm{msi}$ (13000 ksi) (89.63 GPa). As we can analyze for better hemiarthroplasty, implant material needs to be closer to cortical bone, and very few materials satisfy the requirement. Nb35Ti25Zr5Mo with $90 \mathrm{GPa}$ is very much suitable for enamel( $\mathrm{GPa}=40-83)$, i.e., dental application and not orthopedic.

Table 3. Material properties.

\begin{tabular}{|c|c|c|c|}
\hline \multirow{2}{*}{ Properties (Units) } & \multicolumn{3}{|l|}{ Material } \\
\hline & Nb35Ti25Zr5MoAlloy & PEEK & CFR PEEK \\
\hline Density $\left(\mathrm{kg} / \mathrm{mm}^{3}\right)$ & $7.45 \mathrm{E}-06$ & $1.23 \mathrm{E}-06$ & $1.53 \mathrm{E}-06$ \\
\hline Young's modulus (MPa) & $8.96 \mathrm{E}+13$ & 3760 & 4500 \\
\hline Poisson's ratio & 0.4 & 0.3 & 0.3 \\
\hline Bulk modulus (MPa) & $7.47 \mathrm{E}+13$ & 3133.3 & 3750 \\
\hline Shear modulus (MPa) & $3.45 \mathrm{E}+13$ & 1446.2 & 1730.8 \\
\hline
\end{tabular}

The titanium-niobium alloy has good mechanical strength and machinability, and most importantly, it is nontoxic. The high value of young's modulus Ti-based alloys leads to a 
problem called stress-shielding and post-operative complications. A modulus induces better stress transfer along the bone, especially around bone implants. This will ideally safely bone.

With elasticity closer to the bone and superior corrosion resistance, it can become an excellent candidate for orthopedic implant. The elastic modulus of this alloy is around $90 \mathrm{GPa}$ which is quite low considering all bio-metal used in orthopedic implants.

The PEEK material exhibits a lower level of stress shielding as comparable to titanium, which is due to the similar bone mechanical characteristics. Recent studies show, improving the bioactive properties of PEEK at the nanoscale will increase its usability in the human implant. It is also observed that the implants' biocompatibility can be improved by deploying material with lower young's modulus through considering the bone properties. The higher young's modulus results in a higher level of stress shielding observed in the titanium alloys. This can sometimes fail in the local tissue. The PEEK material comprises lower young's modulus values than titanium and is closer to the bone properties, making it an ideal candidate for biomedical implant [61-70].

CFR-PEEK as a material is borrowed from equally stringent aerospace industry [7177].

Peek is quite popular in dental, spine, and cranial due to biocompatibility and other mechanical properties for the last 3 decades.

Carbon fiber Reinforced CFR-PEEK is the version of PEEK that comprises tensile strength and young's modulus snuggest to cortical bone and has been widely deployed in spinal implants.

Regular PEEK has the shortcomings of mechanical strength, making it unsuitable for high load-bearing applications such as knee and hip.

\subsection{Stress shielding.}

The lifespan of hip implants gets reduced by several problems whereas they are designed for a long term like 20 years, deterioration is especially due to stress shielding. The idea is to have a femoral ball made out of PEEK or coated with peek where peek has properties closer to the bone, thus reducing cartilage wear and tear.

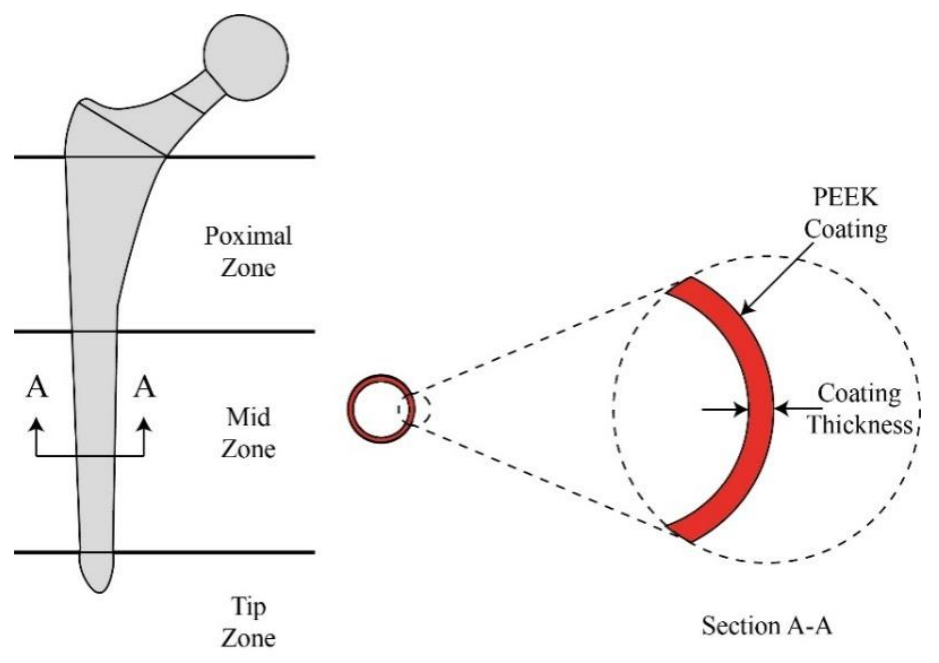

Figure 8. Different zones in hip implant steam and PEEK coating [82].

Our approach could be changed in design and/or materials used like CRF-PEEK for better results, and the PEEK coating on the hip implant is shown in Figure 8. This study 
concludes that coating does improve the life of the hip implants with sufficient coating thickness. This result could be useful in our hip hemiarthroplasty study where the femoral bone is made out of PEEK and no publication until now in this space [78-83].

Farseeinglaxation of hip implants is the major reason for failures in orthopedic surgeries, and the stress shielding in the hip joint with the implant is shown in Figure 9 [8491].

This occurs due to a huge difference in stiffness incompatibility between load-sharing elements such as bone and implant. Usually, less stiff material, i.e., bone, in our case, will lose its density and eventually failing. Stress shielding could be catastrophic in hemiarthroplasty due to native use of tissue which is tough to repair from these damages.

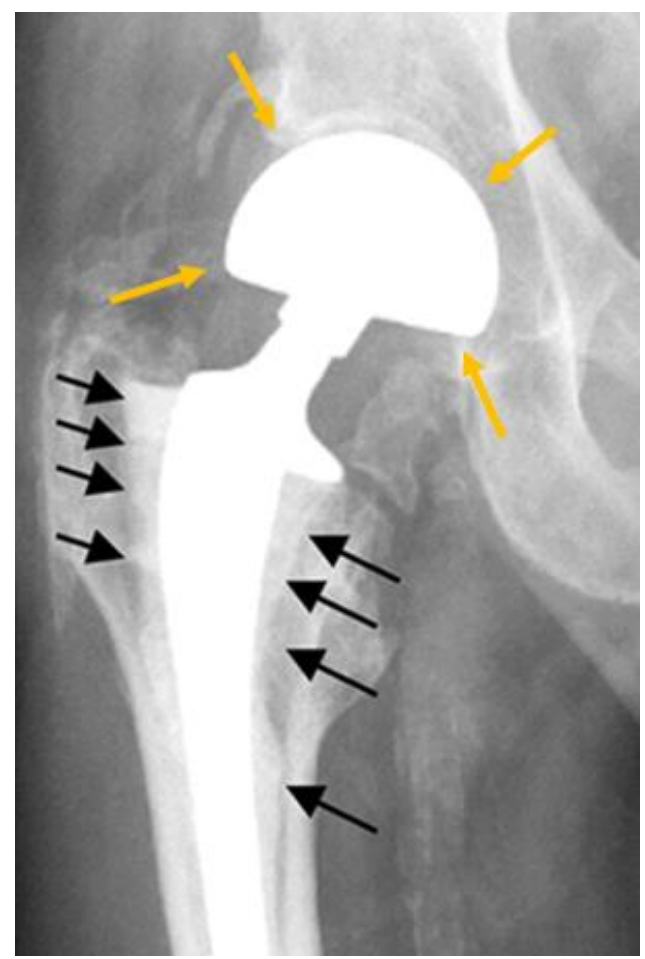

Figure 9. Stress shielding in the hip joint with implant [89].

\subsection{Design optimization.}

Modelling Implants - Hip implants in hemiarthroplasty consist of two main elements called stem and femoral head. Stem is generally made from titanium alloys and goes into the femoral bone, whereas the femoral head is placed in an acetabular cup. We will keep the stem part as titanium alloy for our study and vary the femoral head material with three promising materials: Titanium-niobium alloy (NbTiZrMo alloy), Polyetheretherketone (PEEK), and Carbon fiber Reinforced CFR- PEEK.

These materials are picked because of their excellent biocompatibility and low young's modulus, i.e., properties closer to the bone.

\subsection{Optimization of material.}

Modeling of bone, femoral head, and stem is done using SOLIDWORKS, and reference dimensions were taken from scanning the CT-Scans and were simplified for the process of meshing and further optimizing for accurate and precise data from the FEA analysis. Now, keeping bone properties constant for all three analyses and only femoral head properties was 
changed based on the material under analysis. The stem was excluded from the FEA analysis for reducing computational complications and favor speed. The procedure for the FEA followed in this study is presented diagrammatically in Figure 10.

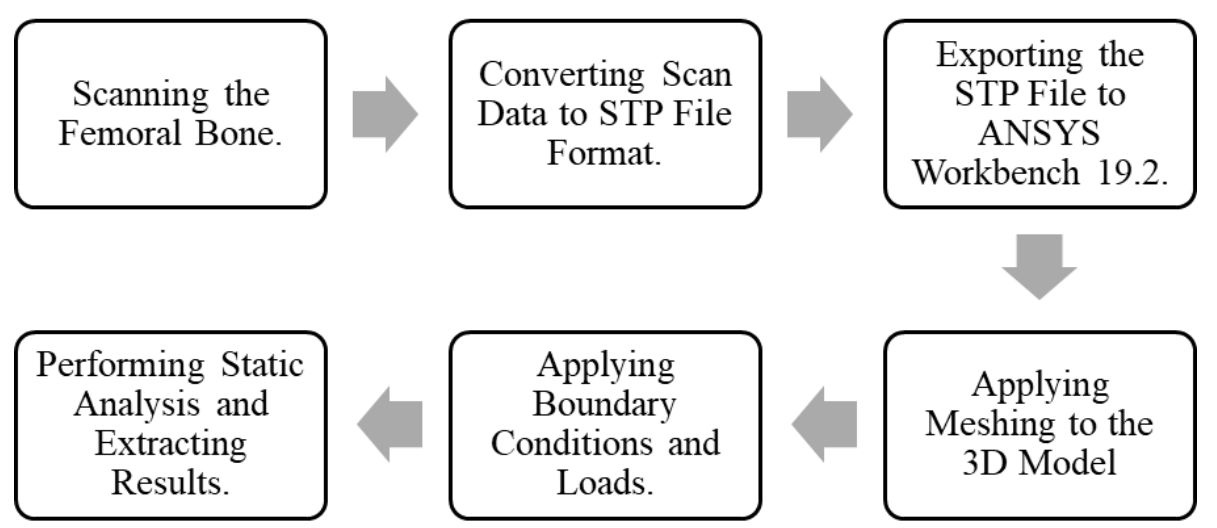

Figure 10. Procedure for the finite element analysis.

\subsection{Basic steps in finite element analysis.}

The three materials are deployed for the finite element analysis, which is explained briefly in the above section with properties. The three-dimensional model of the implant is shown in Figure 11. The process for the finite element analysis in this study comprises different steps, which are given in the following: The actual femur bone is scanned through computed tomography (CT), and the images are further transferred to the commercial SolidWorks software. The three-dimensional model of the femur bone is modeled in 3D modeling software (here SolidWorks), and the implant's modeling is carried out. The implant model is converted into STP file format, is transferred to ANSYS Workbench 19.2 for analysis. The optimum meshing is deployed to the model, and the material properties are also updated for analysis. The boundary conditions are applied, and the contact interaction properties are also applied. The static analysis is performed, and the outcomes are recorded and presented in the study.

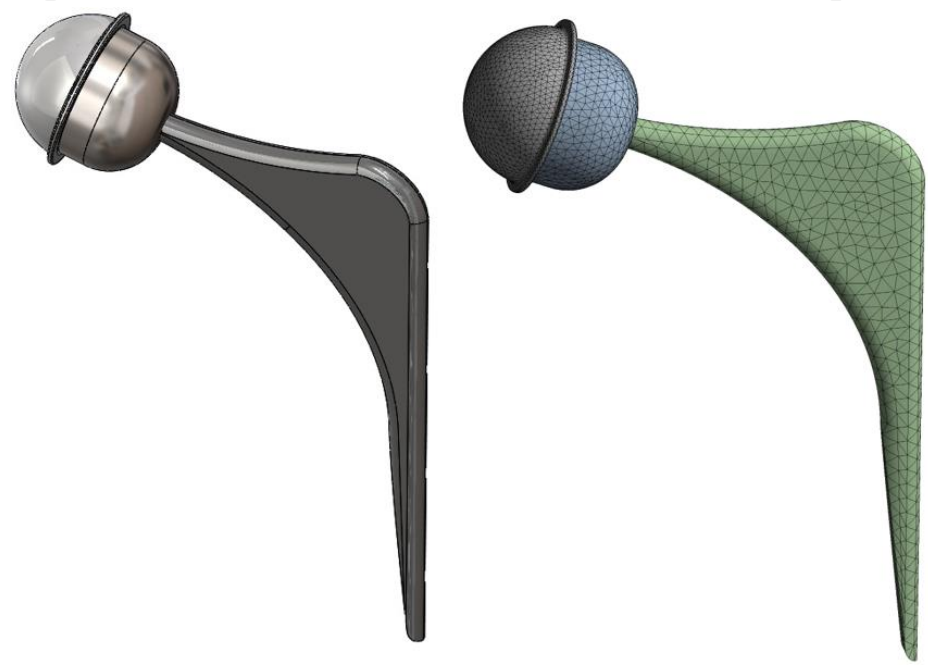

Figure 11. The three-dimensional model of the implant with applied mesh.

\subsection{Meshing.}

The meshing process in FEA refers to discretizing the infinite model to finite number elements for applying the further parameters and analyzing it as a finite model. The meshing is deployed in the ANSYS Workbench 19.2, which is applied as default meshing with tetrahedron 
elements. For the purpose of refinement, the element size of the acetabulum and femur head is altered, the change in aspect ratio and skewness is observed. Finally, the mesh element size for the acetabulum head is selected as $2 \mathrm{~mm}$ and for the femur head $3 \mathrm{~mm}$. The computational time is also a factor in the case of the meshing, which is also considered in this meshing. The FEA mesh model with geometry, aspect ratio, and skewness are shown in Figure 12.

(a)

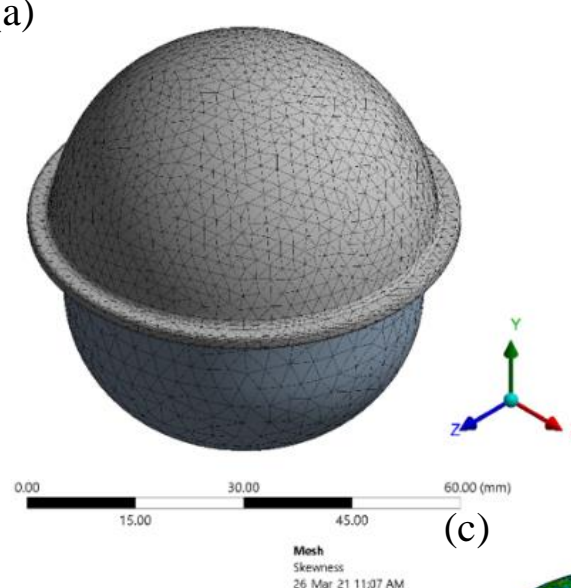

(b)

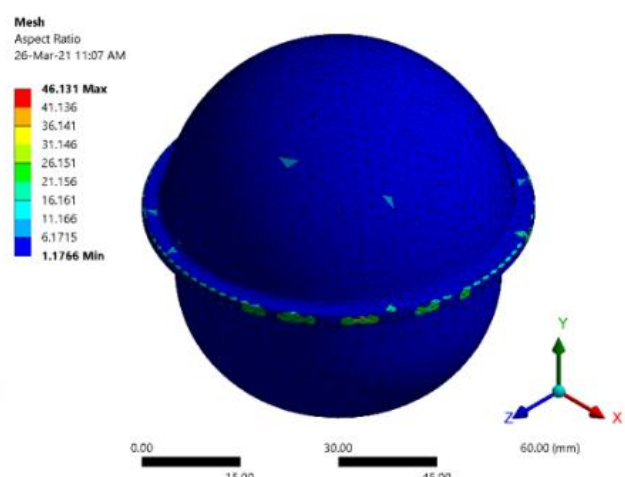

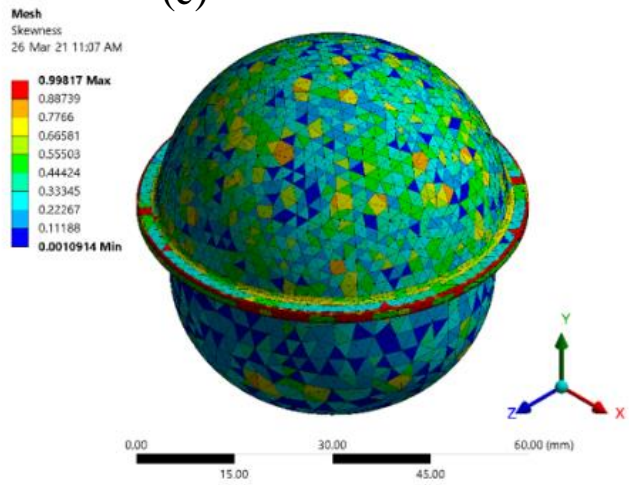

Figure 12. (a) FEA mesh model ; (b) FEA mesh model with respect to aspect ratio, and (c)FEAmesh model with respect to skewness.

\subsection{Boundary conditions.}

Further after completion of the meshing, the boundary conditions are the critical part of the FEA. In this FEA process, the boundary conditions comprise the fixed support, which is applied at the tip of the lip of the acetabulum.

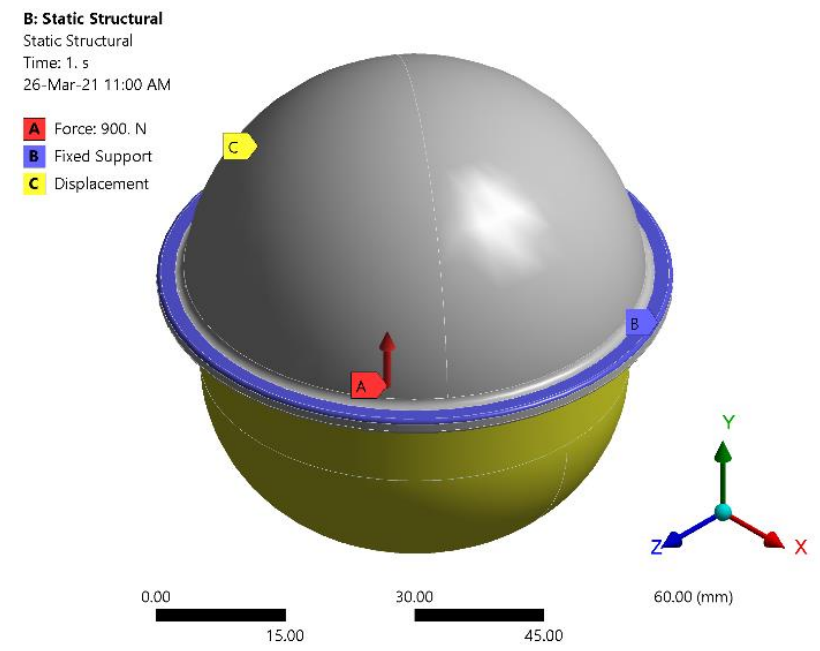

Figure 13. Boundary conditions deployed in FEA. 
The applied load is $900 \mathrm{~N}$, which is also utilized in the analytical method. The load is applied on the femur head bottom section, where the steam is connected to the femur head. The load is applied in a perpendicular direction; in this model, it's in the Y direction. The displacement is applied to the femur head to restrict its motion in other directions. The motion of the femur head is limited in the Y direction freely. The boundary conditions deployed in this study are shown in Figure 13.
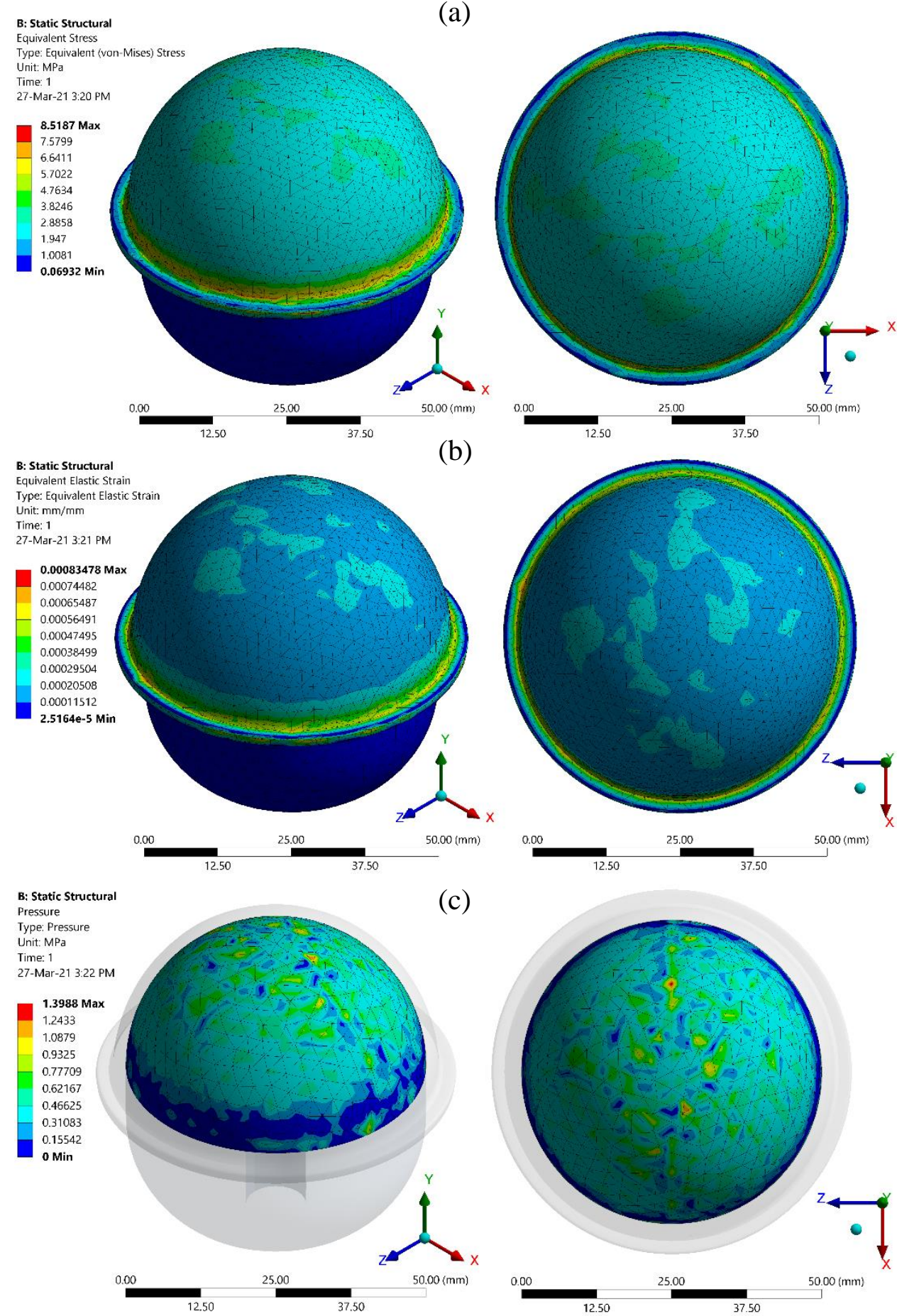

b)
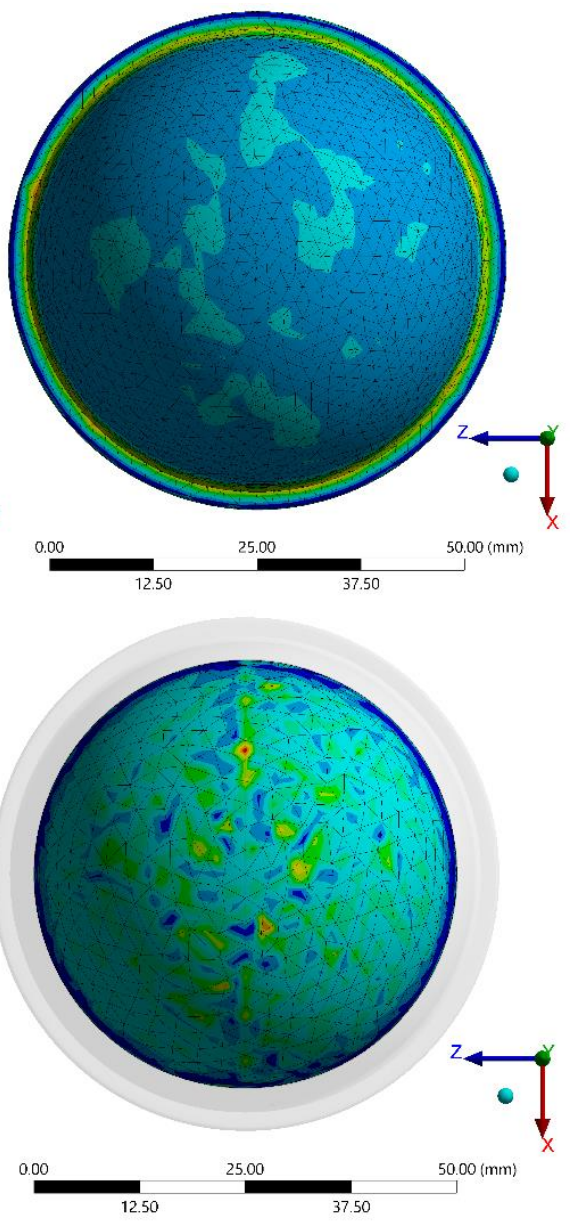

Figure 14.(a) Equivalent Von-Mises stress distribution ; (b) equivalent elastic strain distribution and (c)contact pressure for the NbTiZrMo alloy implant. 


\subsection{Loads and constraints.}

The load applied in this study is a static structural load with a value of $900 \mathrm{~N}$, which was adopted from the analytical method. The direction and the magnitude are discussed in the above section, and the type of force is constant magnitude ramped force. For the purpose of reducing the computational time and simplification, the motion of the femur head is limited in the vertical direction through applying displacement constraints. When it comes to loading, it utilizes only a hip contact force at a point, while loading of the construct and intact bone was conducted using additionally reduced muscle loading together with the hip contact force [71]. The force is applied in a vertical direction at the nodes of an element located at contact points. The load considered for optimization was derived from the realistic loads for testing hip implants for the maximum highest loads of $900 \mathrm{~N}$ body weight.
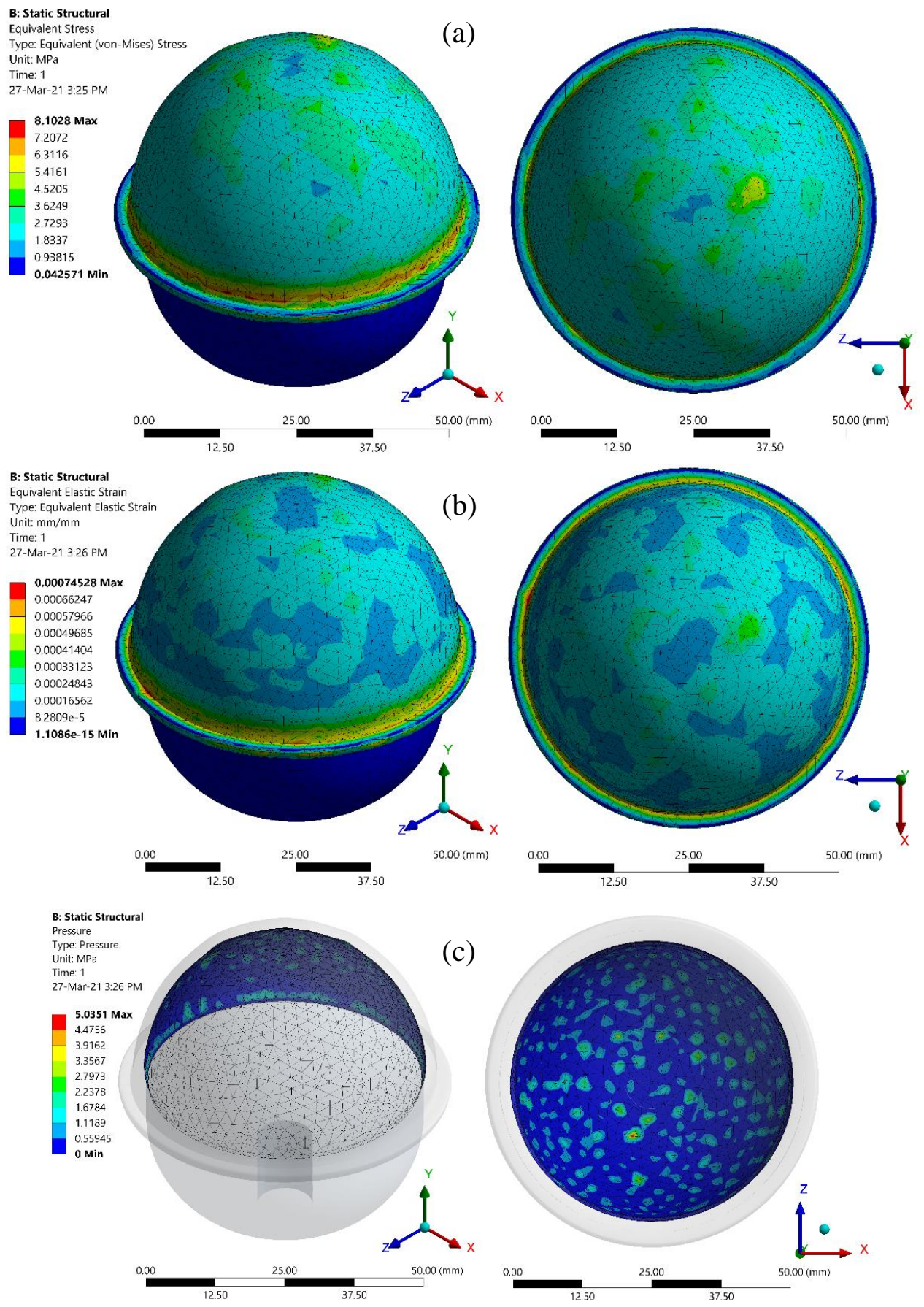

Figure 15. (a) Equivalent Von-Mises stress distribution; (b) equivalent elastic strain distribution and (c) contact pressure for the PEEK implant. 
3.10. NbTiZrMoalloy implant.

The results obtained through the FEA for the NbTiZrMo alloy implant comprise the equivalent Von Mises stress, equivalent elastic strain, and contact pressure, which is shown in Figure 14. It is discovered that the value of the equivalent Von Mises stress obtained is 8.5187 $\mathrm{MPa}$. It is observed that the value of the equivalent elastic strain obtained is $8.3478 \mathrm{E}-4$. It is also observed that the value obtained for the contact pressure is $1.3988 \mathrm{MPa}$.
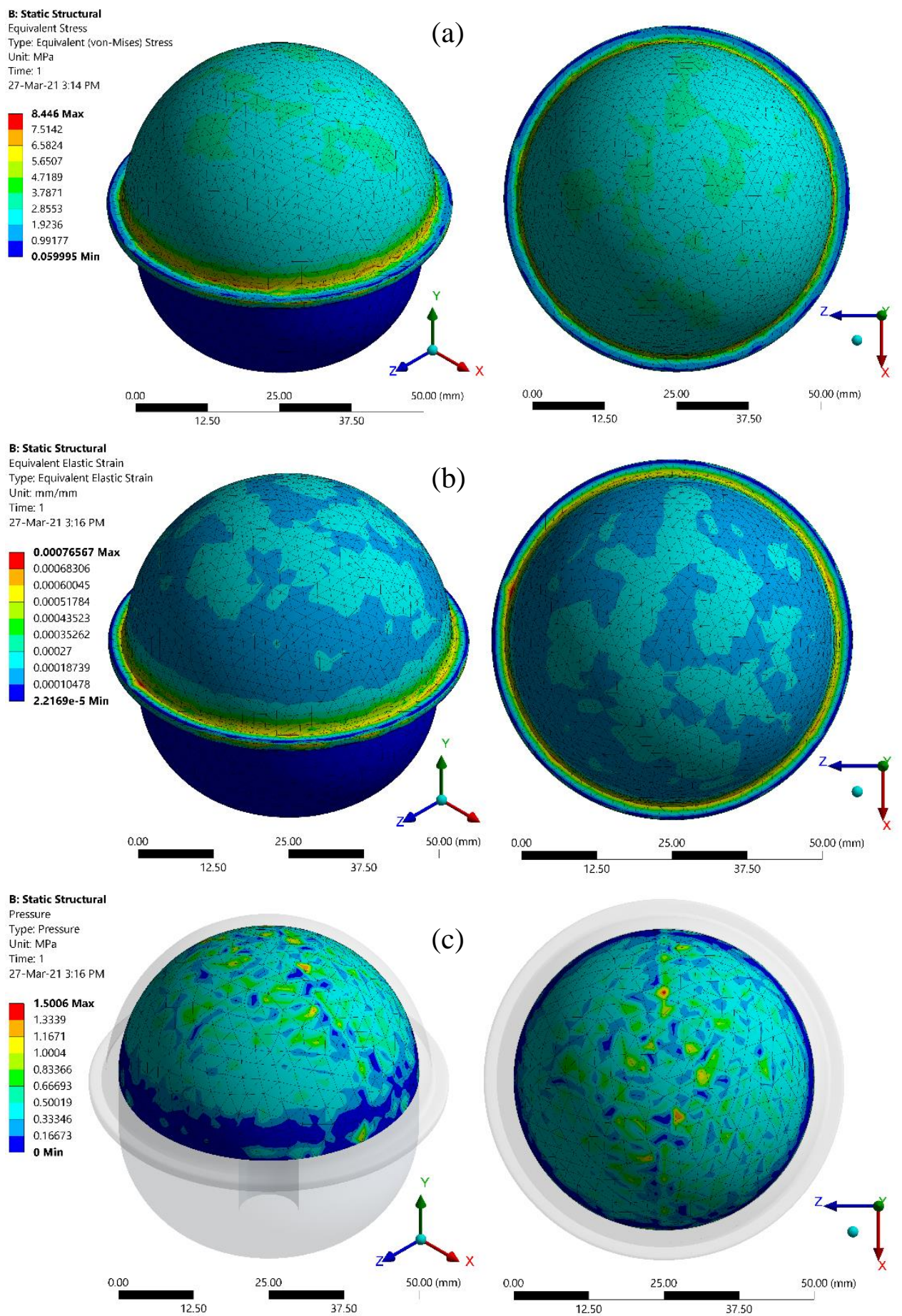

Figure 16.(a) Equivalent Von-Mises stress distribution; (b) equivalent elastic strain distribution and (c) contact pressure for the CFR-PEEK implant.

\subsection{PEEK implant.}

The results obtained through the FEA for the PEEK implant comprise the equivalent Von Mises stress, equivalent elastic strain, and contact pressure, which is shown in Figure. 15. 
It is discovered that the value of the equivalent Von Mises stress obtained is $8.1028 \mathrm{MPa}$. It is observed that the value of the equivalent elastic strain obtained is 7.4528E-4. It is also observed that the value obtained for the contact pressure is $5.0351 \mathrm{MPa}$.

\subsection{CFR-PEEK implant.}

The results obtained through the FEA for the PEEK implant comprise the equivalent Von Mises stress, equivalent elastic strain, and contact pressure, which is shown in Figure 16. It is discovered that the value of the equivalent Von Mises stress obtained is 8.446 MPa. It is observed that the value of the equivalent elastic strain obtained is 7.6567E-4. It is also observed that the value obtained for the contact pressure is $1.5006 \mathrm{MPa}$. The FEA results for all the materials in tabular form are shown in Table 4.

Table 4. FEA results of selected materials.

\begin{tabular}{l|l|l|l} 
Material & $\begin{array}{l}\text { Equivalent Elastic } \\
\text { Strain }\end{array}$ & $\begin{array}{l}\text { Contact pressure in } \\
\text { MPa }\end{array}$ & $\begin{array}{l}\text { Von-Mises stress at } \\
\text { bone in MPa }\end{array}$ \\
\hline NbTiZrMo Alloy & $8.3478 \mathrm{e}-4$ & 1.3988 & 8.5187 \\
\hline PEEK & $7.4528 \mathrm{e}-4$ & 5.0351 & 8.1028 \\
\hline CFR-PEEK & $7.5657 \mathrm{e}-4$ & 1.5006 & 8.446
\end{tabular}

\section{Conclusions}

This work is carried out the analytical and finite element analysis, whereas it can clearly conclude that CFR-PEEK is the suitable material considering the amount of contact pressure of bone and contact pressure on the head. The value sits comfortably between NbTiZrMo alloys and PEEK, ensuring longevity and mitigation of stress shielding effect into these materials. FEA results clearly demonstrate that niobium alloy exhibits the highest contact pressure on the bone, which will deteriorate the natural tissue and cartilage in a short duration and a relatively high-stress shielding effect compared to other materials. On the other hand, PEEK shows the highest deformation in implant materials, where we can safely conclude that implant longevity is questionable. As stated, above CFR PEEK sits between these two materials giving the best of both worlds in terms of implant longevity and better tissue damage.

The CFR-PEEK material comprises a higher value of von-Mises stresses than the PEEK material results, but the contact pressure for the PEEK material is way higher than that of the CFR-PEEK material implant. In analytical analysis, the maximum peak stress value obtained is for the fast walking activity, which is $11.9 \mathrm{MPa}$, and for CFR-PEEK material implant, the Von-Mises stresses at the head and boneis8.446 MPa, which are comparatively very lower values. It is also observed that all the Von-Mises stresses obtained in FEA for all three materials are lower than the maximum peak stress value in analytical analysis. It is also discovered that the Von-Mises stress value for CFR-PEEK material implant is $8.446 \mathrm{MPa}$, which higher than the minimum peak stress value obtained in walking slow activity in analytical analysis, which is $5.3 \mathrm{MPa}$. It is eventually concluded that the CFR-PEEK material is ideal for the hip implant compared to other materials results obtained in this study.

\section{Funding}

This research received no external funding. 


\section{Acknowledgments}

Shailesh S. Pimpale thanks Dr. R. K. Jain, Director, JSPM's, Rajarshi Shahu College of Engineering Research Center, Tathawade, Pune, for going through the manuscript and providing valuable comments and suggestions for improving the quality of this work.

\section{Conflicts of Interest}

The authors declare no conflict of interest.

\section{References}

1. Kumar, K. C. N.; Tandon, T; Silori, P.; Shaikh, A. Biomechanical Stress Analysis of a Human Femur Bone Using ANSYS. Materials Today: Proceedings 2015, 2, 2115-2120, https://doi.org/10.1016/j.matpr.2015.07.211.

2. San Antonio, T.; Ciaccia, M.; Müller-Karger, C.; Casanova, E. Orientation of orthotropic material properties in a femur FE model: A method based on the principal stresses directions. Medical Engineering \& Physics 2012, 34, 914-919, https://doi.org/10.1016/j.medengphy.2011.10.008.

3. Jade, S.; Tamvada, K. H.; Strait, D. S.; Grosse, I. R. Finite element analysis of a femur to deconstruct the paradox of bone curvature. Journal of Theoretical Biology 2014, 341, 53-63, https://doi.org/10.1016/j.jtbi.2013.09.012.

4. Yousif, A. E. Biomechanical Analysis of the human femur bone during normal walking and standing up. IOSR Journal of Engineering 2012, 2, 13-19, https://doi.org/10.9790/3021-02851319.

5. Berney, M. J.; Gibbons, J.; Fitzgerald, M. K.; Cardiff, D. P.; Leonard, M. Computational modelling of forces acting on the femur in acetabular fractures: A finite element analysis study. J Orthop 2019, 16, 603-618, https://doi.org/10.1016/j.jor.2019.06.004.

6. White, G.; Kanakaris, N. K.; Faour, O.; Valverde, J. A.; Martin, M. A.; Giannoudis, P. V. Quadrilateral plate fractures of the acetabulum: an update. Injury 2013, 44, 159-167, https://doi.org/10.1016/j.injury.2012.10.010.

7. Ferguson, T. A.; Patel, R.; Bhandari, M.; Matta, J. M. Fractures of the acetabulum in patients aged 60 years and older: an epidemiological and radiological study. J Bone Joint Surg Br 2010, 92, 250-257, https://doi.org/10.1302/0301-620X.92B2.22488.

8. Cardiff, P.; Karač, A.; FitzPatrick, D.; Ivanković, A. Development of a hip joint model for finite volume simulations. J Biomech Eng 2014, 136, 011006, https://doi.org/10.1115/1.4025776.

9. Li B.; Aspden, R. M. Material properties of bone from the femoral neck and calcar femorale of patients with osteoporosis or osteoarthritis. Osteoporos Int 1997, 7, 450-456, https://doi.org/10.1007/s001980050032.

10. Rahaman, M. N.; Huang, T.; Yao, A.; Bal, B. S.; Li, Y. SiC nanoparticle-reinforced Al2O3-Nb composite as a potential femoral head material in total hip arthroplasty. Materials Science and Engineering: C 2010, 30, 1197-1203, https://doi.org/10.1016/j.msec.2010.06.012.

11. Bishop, N. E.; Waldow, F.; Morlock, M. M. Friction moments of large metal-on-metal hip joint bearings and other modern designs. Medical Engineering \& Physics 2008, 30, 1057-1064, https://doi.org/10.1016/j.medengphy.2008.01.001.

12. Abu-Amer, Y.; Darwech, I.; Clohisy, J. C. Aseptic loosening of total joint replacements: mechanisms underlying osteolysis and potential therapies. Arthritis Research \& Therapy 2007, 9, S6, https://doi.org/10.1186/ar2170.

13. Brockett, C.; Williams, S.; Jin, Z.; Isaac, G.; Fisher, J. Friction of total hip replacements with different bearings and loading conditions. Journal of Biomedical Materials Research Part B: Applied Biomaterials 2007, 81B, 508-515, https://doi.org/10.1002/jbm.b.30691.

14. Krenn,V.; Morawietz,L.; Perino,G.;Kienapfel, H.; Ascherl,R.; Hassenpflug, G.J.; Thomsen, M.;Thomas, P.; Huber, M.; Kendoff, D.; Baumhoer, D.; Krukemeyer, M.G.; Natu, S.; Boettner, F.; Zustin, J.; Kölbel, B.; Rüther, W.; Kretzer, J.P.; Gehrke, T. Revised histopathological consensus classification of joint implant related pathology. Pathology -Research and Practice 2014, 210, 779-786, https://doi.org/10.1016/j.prp.2014.09.017. 
15. Zietz, C.; Bergschmidt, P.; Lange, R.; Mittelmeier, W.; Bader, R. Third-Body Abrasive Wear of Tibial Polyethylene Inserts Combined with Metallic and Ceramic Femoral Components in a Knee Simulator Study. Int J Artif Organs 2013, 36, 47-55, https://doi.org/10.5301/ijao.5000189.

16. Bader, R.; Bergschmidt, P.; Fritsche, A.;Ansorge, S.; Thomas, Fr.; Mittelmeier, W. Alternative Werkstoffe und Lösungen in der Knieendoprothetik für Patienten mit Metallallergie. Orthopäde 2008, 37, 136-142, https://doi.org/10.1007/s00132-007-1189-x.

17. Que, L.D.; Topoleski, T. Third-body wear of cobalt-chromium-molybdenum implant alloys initiated by bone and poly(methyl methacrylate) particles. Journal of Biomedical Materials Research 2000, 50, 322330,https://doi.org/10.1002/(SICI)1097-4636(20000605)50:3<322::AID-BM5>3.0.CO;2-U.

18. Sorimachi, T.; Clarke, I. C.; Williams, P. A.; Gustafson, A.; Yamamoto, K. Third-body abrasive wear challenge of $32 \mathrm{~mm}$ conventional and $44 \mathrm{~mm}$ highly crosslinked polyethylene liners in a hip simulator model. Proc Inst Mech Eng H 2009, 223, 607-623, https://doi.org/10.1243/09544119jeim562.

19. Desjardins, J. D.; Banks, S. A.; Benson, L. C.; Pace, T.; LaBerge, M. A direct comparison of patient and force-controlled simulator total knee replacement kinematics. Journal of Biomechanics 2007, 40, 3458-3466, https://doi.org/10.1016/j.jbiomech.2007.05.022.

20. Sarkar, D.; Mandal, S.; Reddy, B. S.; Bhaskar, N.; Sundaresh, D. C.; Basu, B. ZrO2-toughened Al2O3-based near-net shaped femoral head: Unique fabrication approach, 3D microstructure, burst strength and muscle cell response. Materials Science and Engineering: C 2017, 77, 1216-1227, https://doi.org/10.1016/j.msec.2017.03.123.

21. Pakhaliuk, V.; Polyakov, A.; Kalinin, M.; Kramar, V. Improving the Finite Element Simulation of Wear of Total Hip Prosthesis' Spherical Joint with the Polymeric Component. Procedia Engineering 2015, 100, 539548, https://doi.org/10.1016/j.proeng.2015.01.401.

22. Sarkar, D.; Reddy, B. S.; Mandal, S.; RaviSankar, M.; Basu, B. Uniaxial Compaction-Based Manufacturing Strategy and 3D Microstructural Evaluation of Near-Net-Shaped ZrO2-Toughened Al2O3 Acetabular Socket. Advanced Engineering Materials 2016, 18, 1634-1644, https://doi.org/10.1002/adem.201600147.

23. Galanis N. I.; Manolakos, D. E. Surface roughness prediction in turning of femoral head. Int J Adv Manuf Technol 2010, 51, 79-86, https://doi.org/10.1007/s00170-010-2616-4.

24. Affolter, C.; Weisse, B.; Stutz, A.; Köbel, S.; Terrasi, G. P. Optimization of the stress distribution in ceramic femoral heads by means of finite element methods. Proc Inst Mech Eng $H$ 2009, 223, 237-248, https://doi.org/10.1243/09544119jeim429.

25. Huet, R; Sakona, A.; Kurtz, S. M. Strength and reliability of alumina ceramic femoral heads: Review of design, testing, and retrieval analysis. Journal of the Mechanical Behavior of Biomedical Materials 2011, 4, 476-483, https://doi.org/10.1016/j.jmbbm.2010.12.010.

26. Thrivikraman, G.; Mallik, P. K.; Basu, B. Substrate conductivity dependent modulation of cell proliferation and differentiation in vitro. Biomaterials 2013, 34, 85, https://doi.org/10.1016/j.biomaterials.2013.05.076.

27. Lee, R; Essner, A.; Wang, A.; Jaffe, W. L. Scratch and wear performance of prosthetic femoral head components against crosslinked UHMWPE sockets. Wear 2009, 267, 1915-1921, https://doi.org/10.1016/j.wear.2009.03.034.

28. Walter, W. L.; O'Toole, G. C.; Walter, W. K.; Ellis, A.; Zicat, B. A. Squeaking in Ceramic-on-Ceramic Hips: The Importance of Acetabular Component Orientation. The Journal of Arthroplasty 2007, 22, 496-503, https://doi.org/10.1016/j.arth.2006.06.018.

29. Keurentjes, J. C.; Kuipers, R. M.; Wever, D. J.; Schreurs, B. W. High incidence of squeaking in THAs with alumina ceramic-on-ceramic bearings. Clin Orthop Relat Res 2008, 466, 1438-1443, https://doi.org/10.1007/s11999-008-0177-8.

30. MacDonald, S J; McCalden, R W; Chess, D G; Bourne, R B; Rorabeck, C H ; Cleland, D; Leung, F. Metalon-metal versus polyethylene in hip arthroplasty: a randomized clinical trial. Clin Orthop Relat Res 2003,406, 282-296, https://doi.org/10.1097/01.blo.0000043066.62337.9d.

31. Savarino, L.; Granchi, D.; Ciapetti, G.;Cenni, E.; Nardi Pantoli, A.; Rotini, R.; Veronesi, C.A.; Baldini, N.; Giunti, A. Ion release in patients with metal-on-metal hip bearings in total joint replacement: a comparison with metal-on-polyethylene bearings. J Biomed Mater Res 2002, 63, 467-474, https://doi.org/10.1002/jbm.10299.

32. Dumbleton, J. H.; D’Antonio, J. A.; Manley, M. T.; Capello, W. N.; Wang, A. The basis for a secondgeneration highly cross-linked UHMWPE. Clin Orthop Relat Res 2006, 453, 265-271, https://doi.org/10.1097/01.blo.0000238856.61862.7d. 
33. Wang, A.; Yau, S.-S.; Essner, A.; Herrera, L.; Manley, M.; Dumbleton, J. A highly crosslinked UHMWPE for CR and PS total knee arthroplasties. J Arthroplasty 2008, 23, 559-566, https://doi.org/10.1016/j.arth.2007.05.007.

34. Bowsher J. G.; Shelton, J. A hip simulator study of the influence of patient activity level on wear of crosslinked polyethylene under smooth and roughened femoral heads. Wear 2001, 250, 167-179, https://doi.org/10.1016/S0043-1648(01)00619-6.

35. Lee, R.; Cardinale, M.; Loving, L.; Longaray, J.; Essner, A.; Wang, A.; Ward, D. Abrasion of ceramic femoral heads and its effects on pe wear. Orthopaedic Proceedings 2009, 91-B(no. SUPP_III), 474-474, https://10.1302/0301-620X.91BSUPP_III.0910474a.

36. Wang, A.; Essner, A.; Schmidig, G. The effects of lubricant composition on in vitro wear testing of polymeric acetabular components. J Biomed Mater Res B Appl Biomater 2004, 68, 45-52, https://doi.org/10.1002/jbm.b.10077.

37. Good, V.; Ries, M.; Barrack, R. L.; Widding, K.; Hunter, G.; Heuer, D. Reduced wear with oxidized zirconium femoral heads. J Bone Joint Surg Am 2003, 85-A(Suppl 4), 105-110, https://doi.org/10.2106/00004623-200300004-00013.

38. Kop, A. M.; Whitewood, C.; Johnston, D. J. L. Damage of oxinium femoral heads subsequent to hip arthroplasty dislocation three retrieval case studies. J Arthroplasty 2007, 22, 775-779, https://doi.org/10.1016/j.arth.2006.07.005.

39. Wang, Q. J.; Chung, Y.-W.Eds., Encyclopedia of Tribology. Springer US 2013, https://doi.org/10.1007/9780-387-92897-5

40. Petersen, P. B.; Larsen, M.L.; Jorgensen, C.C.; Kehlet, H. Venous thromboembolism after fast-track elective revision hip and knee arthroplasty - A multicentre cohort study of 2814 unselected consecutive procedures. Thrombosis Research 2021, 199, 101-105, https://doi.org/10.1016/j.thromres.2021.01.003.

41. Bailey, A.; Eisen, I.; Palmer, A.; Paul, E.; Grammatopoulos, G. Preoperative Anemia in Primary Arthroplasty Patients - Prevalence, Influence on Outcome, and the Effect of Treatment. The Journal of Arthroplasty 2021, https://doi.org/10.1016/j.arth.2021.01.018.

42. Wood, T. J.; Gazendam, A. M.; Kabali,C.B.Postoperative Outcomes Following Total Hip and Knee Arthroplasty in Patients with Pain Catastrophizing, Anxiety, or Depression. The Journal of Arthroplasty 2021, https://doi.org/10.1016/j.arth.2021.02.018.

43. Girbino, K. L.; et al. Understanding the Main Predictors of Length of Stay After Total Hip Arthroplasty: Patient-Related or Procedure-Related Risk Factors?. The Journal of Arthroplasty 2020, https://doi.org/10.1016/j.arth.2020.11.029.

44. Chatterjee P.; Chakraborty, S. Material selection using preferential ranking methods. Materials \& Design 2012, 35, 384-393, https://doi.org/10.1016/j.matdes.2011.09.027.

45. Murphy, E. P.; Fenelon, C.; Akoud, A. I.; Kearns, S. R.; Shannon, F. J.; Murphy, C. G. Perioperative Mortality and Periprosthetic Fracture: A Single-Center Experience of 857 Uncemented Hemiarthroplasties for Displaced Femoral Neck Fractures. The Journal of Arthroplasty 2021, 36, 2044-2048, https://doi.org/10.1016/j.arth.2021.01.055.

46. Schmitz, P. P.; Van Leent, E. A. P.; de Jong, L. D.; van Susante, J. L. C.; Somford, M. P. The (un)necessity of regular post-operative follow-up of hemiarthroplasty for femoral neck fractures. Injury 2021, https://doi.org/10.1016/j.injury.2021.02.051.

47. Robin de Bot, R. T. A. L.; Veldman, H. D.; Eurlings, R.; Stevens, J.; Hermus, J. P. S.; Witlox, A. M. Metallic Hemiarthroplasty or Arthrodesis of the First Metatarsophalangeal Joint as Treatment for Hallux Rigidus: a systematic review and meta-analysis. Foot and Ankle Surgery 2021, https://doi.org/10.1016/j.fas.2021.03.004.

48. Barták, V.; Heřt, J.; Štědrý, J.; Popelka, S.; Popelka, S.; Hromádka, R. Long-term results of total joint arthroplasty and phalangeal hemiarthroplasty of the first metatarsophalangeal joint using the ToeFit Plus ${ }^{\mathrm{TM}}$ system. Foot and Ankle Surgery 2021, https://doi.org/10.1016/j.fas.2021.01.014.

49. Smith, T. J.; Shah, S. S.; Peterson, J. W.; Ross, G. The modern use of the extended humeral head (cuff tear arthropathy) hemiarthroplasty. JSES International $\mathbf{2 0 2 1 ,} \quad 5, \quad$ 142-148, https://doi.org/10.1016/j.jseint.2020.09.011.

50. Phruetthiphat, O.; Lawanprasert, A.; Khuangsirikul, S.; Heebtamai, D.; Chotanaphuti, T. Effectiveness of Periarticular Injection After Bipolar Hemiarthroplasty for Displaced Femoral Neck Fracture in Elderly Patients: A Double Blinded Randomized, Controlled Study. The Journal of Arthroplasty 2021, https://doi.org/10.1016/j.arth.2021.01.017. 
51. Briggs , T.W. R.; Kayani , B.; Tai , S.; Pollock, R.C.; Cannon , S. R.; Blunn, G. W.; Carrington, R. W. J . Metal-on-polyethylene versus metal-on-metal bearing surfaces in total hip arthroplasty: a prospective randomised study investigating metal ion levels and chromosomal aberrations in peripheral lymphocytes. Bone Joint J 2015, 97-B, 1183-1191, https://doi.org/10.1302/0301-620X.97B9.34824.

52. Das S. S.; Chakraborti, P. Development of Biomaterial for Total Hip Joint Replacement. IOP Conf. Ser.: Mater. Sci. Eng. 2018, 377, 012177, https://doi.org/10.1088/1757-899X/377/1/012177.

53. Keegan, G. M.; Learmonth, I. D.; Case, C. P. Orthopaedic metals and their potential toxicity in the arthroplasty patient: A review of current knowledge and future strategies. J Bone Joint Surg Br 2007, 89, 567-573, https://doi.org/10.1302/0301-620X.89B5.18903.

54. Ladon, D.; Doherty, A.; Newson, R.; Turner, J.; Bhamra, M. and Case, C. P. Changes in metal levels and chromosome aberrations in the peripheral blood of patients after metal-on-metal hip arthroplasty. The Journal of Arthroplasty 2004,19, 78-83, https://doi.org/10.1016/j.arth.2004.09.010.

55. Haddad, F. S.; Thakrar, R. R.; Hart, A. J.; Skinner, J. A.;Nargol, A. V. F.; Nolan, J. F.; Gill, H. S.;Murray, D. W.; Blom, A. W.; Case, C. P. Metal-on-metal bearings: the evidence so far. J Bone Joint Surg Br 2011, 93, 572-579, https://doi.org/10.1302/0301-620X.93B4.26429.

56. Bierbaum, B. E.; Nairus, J.; Kuesis, D.; Morrison, J. C.; Ward, D. Ceramic-on-ceramic bearings in total hip arthroplasty. Clin Orthop Relat Res 2002, 405, 158-163, https://doi.org/10.1097/00003086-20021200000019.

57. Daniel, J.; Pynsent, P. B.; McMinn, D. J. W. Metal-on-metal resurfacing of the hip in patients under the age of 55 years with osteoarthritis. J Bone Joint Surg Br 2004, 86, 177-184, https://doi.org/10.1302/0301620X.86B2.14600.

58. Hans-Georg ; Willert; Gottfried, H.; Buchhorn; Afshin; Fayyazi; Renata; Flury; Markus; Windler; Georg Köster; Christoph, H.; Lohmann .Metal-on-metal bearings and hypersensitivity in patients with artificial hip joints. A clinical and histomorphological study. J Bone Joint Surg Am 2005, 87,28-36, https://doi.org/10.2106/jbjs.a.02039pp.

59. David, J. W. "Handbook of Surface Metrology," Routledge \& CRC Press.2021. https://www.routledge.com/Handbook-of-Surface-Metrology/Whitehouse/p/book/9780750300391.

60. Daniel, M.; Antolic V.; Iglic, A.; Kralj-Iglic . Determination of contact hip stress from nomograms based on mathematical model. Med Eng Phys 2001, 23, 347-357, https://doi.org/10.1016/S1350-4533(01)00051-0.

61. Chenchen Liu ; Jianfei Bai ; YueWang ; Liang Chen ; Defei Wang; Shanling Ni; Hong Liu.The effects of three cold plasma treatments on the osteogenic activity and antibacterial property of PEEK. Dental Materials 2021, 37, 81-93,https://doi.org/10.1016/j.dental.2020.10.007.

62. Wang, B.; Yu, S.; Mao, J.; Wang, Y.; Li, M.; Li, X. Effect of basalt fiber on tribological and mechanical properties of polyether-ether-ketone (PEEK) composites. Composite Structures 2021, 266, 113847, https://doi.org/10.1016/j.compstruct.2021.113847.

63. Yang, X. G.; Duan, D. L.; Zhang, X.; Jiang, S. L.; Li, S.; Zhang, H. C. Tensile behaviour of poly(etherether-ketone) (PEEK)/Ni foam co-continuous phase composites. Journal of Materials Research and Technology 2021, 10, 110-120, https://doi.org/10.1016/j.jmrt.2020.12.023.

64. Escobar, M.; Souza, J. C. M.; Barra, G. M. O.; Fredel, M. C.; Özcan, M. ; Henriques, B. On the synergistic effect of sulfonic functionalization and acidic adhesive conditioning to enhance the adhesion of PEEK to resin-matrix composites. Dental Materials 2021, 37, 741-754, https://doi.org/10.1016/j.dental.2021.01.017.

65. Mourya, A.; Nahar, R.; Mishra, S. K.; Chowdhary, R. Stress distribution around different abutments on titanium and CFR-PEEK implant with different prosthetic crowns under parafunctional loading: A 3D FEA study. Journal of Oral Biology and Craniofacial Research 2021, 11, 313-320, https://doi.org/10.1016/j.jobcr.2021.03.005.

66. Niu, Y.; Zheng, S.; Song, P.; Zhang, X.; Wang, C. Mechanical and thermal properties of PEEK composites by incorporating inorganic particles modified phosphates. Composites Part B: Engineering 2021, 212, 108715, https://doi.org/10.1016/j.compositesb.2021.108715.

67. Xin , H.; Riujuan, L.; Zhang, L.; Jun Hong, J.; Nairu, H.; SaSa , G.; ZhongMin ,J. A comparative biotribological study of self-mated PEEK and its composites under bovine serum lubrication. Biotribology 2021, 26, 100171, https://doi.org/10.1016/j.biotri.2021.100171.

68. Verma, S.; Sharma, N.; Kango, S.; Sharma, S. Developments of PEEK (Polyetheretherketone) as a biomedical material: A focused review. European Polymer Journal 2021, 147, 110295,https://doi.org/10.1016/j.eurpolymj.2021.110295. 
69. Lyu, H.; Jiang, N.; Li, Y.; Lee, H.; Zhang, D. Enhanced interfacial and mechanical properties of carbon fiber/PEEK composites by hydroxylated PEEK and carbon nanotubes. Composites Part A: Applied Science and Manufacturing 2021, 145, 106364, https://doi.org/10.1016/j.compositesa.2021.106364.

70. Bankole. I. Oladapo and Zahedi, S. A. Improving bioactivity and strength of PEEK composite polymer for bone application. Materials Chemistry and Physics 2021, 266, 124485, https://doi.org/10.1016/j.matchemphys.2021.124485.

71. Sun, C.; Wang, L.; Kang, J.; Li, D.; Jin, Z. Biomechanical Optimization of Elastic Modulus Distribution in Porous Femoral Stem for Artificial Hip Joints. J Bionic Eng 2018, 15, 693-702, https://doi.org/10.1007/s42235-018-0057-1.

72. Wilkinson, J. M.; Hamer, A. J.; Rogers, A.; Stockley, I. ; Eastell, R. Bone mineral density and biochemical markers of bone turnover in aseptic loosening after total hip arthroplasty. J Orthop Res 2003, 21, 691-696, https://doi.org/10.1016/S0736-0266(02)00237-1.

73. Gibson, I.; Cheung, L.K.; Chow, S.P.; Cheung, W.L.; Beh, S.L .; Savalani , M.; Lee, S.H. The use of rapid prototyping to assist medical applications. Rapid Prototyping Journal 2006, 12, 53-58, https://doi.org/10.1108/13552540610637273.

74. Gong, H.; Wu, W.; Fang, J.; Dong, X.; Zhao, M.; Guo, T. Effects of Materials of Cementless Femoral Stem on the Functional Adaptation of Bone. Journal of Bionic Engineering 2012, 9, 66-74, https://doi.org/10.1016/S1672-6529(11)60098-X.

75. Yang, Y. Li, C.; Zhao, H.; Qu, S.; Li, X. and Li, Y. New Developments of Ti-Based Alloys for Biomedical Applications. Materials (Basel) 2014, 7, 1709-1800, https://doi.org/10.3390/ma7031709.

76. Huiskes, R.; Weinans, H. and van Rietbergen, B. The relationship between stress shielding and bone resorption around total hip stems and the effects of flexible materials. Clin Orthop Relat Res 1992, 274, 124134, https://doi.org/10.1097/00003086-199201000-00014.

77. Arabnejad, S.; Johnston, B.; Tanzer, M.; Pasini, D. Fully porous 3D printed titanium femoral stem to reduce stress-shielding following total hip arthroplasty. J Orthop Res 2017, 35, 1774-1783, https://doi.org/10.1002/jor.23445.

78. Najeeb, S.; Zafar, M. S.; Khurshid, Z.; Siddiqui, F. Applications of polyetheretherketone (PEEK) in oral implantology and prosthodontics. J Prosthodont Res 2016, 60, 12-19, https://doi.org/10.1016/j.jpor.2015.10.001.

79. Barkarmo, S .; Andersson, M; Currie,F.; Kjellin, P.; Jimbo , R.; Johansson,CB.; Stenport,V. Enhanced bone healing around nanohydroxyapatite-coated polyetheretherketone implants: An experimental study in rabbit bone. J Biomater Appl 2014, 29, 737-747, https://doi.org/10.1177/0885328214542854.

80. Barkarmo, S.; Wennerberg, A.; Hoffman, M.; Kjellin, P.; Breding, K.; Handa, P.; Stenport, V. Nanohydroxyapatite-coated PEEK implants: A pilot study in rabbit bone. Journal of Biomedical Materials Research Part A 2013, 101A, 465-471, https://doi.org/10.1002/jbm.a.34358.

81. Rabiei, A.; Sandukas, S. Processing and evaluation of bioactive coatings on polymeric implants. Journal of Biomedical Materials Research Part A 2013,101A,2621-2629, https://doi.org/10.1002/jbm.a.34557.

82. Anguiano-Sanchez, J.; Martinez-Romero, O.; R. Siller, H.; Diaz-Elizondo J.A.;

Flores-Villalba, E.; Rodriguez, C.A. Influence of PEEK Coating on Hip Implant Stress Shielding: A

Finite Element Analysis. Computational and Mathematical Methods in Medicine 2016, 6183679, https://doi.org/10.1155/2016/6183679.

83. Toth, J. M.; Wang, M.; Estes, B. T.; Scifert, J. L.; Seim, H. B.; Turner, A. S. Polyetheretherketone as a $\begin{array}{lllll}\text { biomaterial for } & \text { spinal } & \text { Biomaterials } & \text { 2006,27, } & \text { 324-334, }\end{array}$ https://doi.org/10.1016/j.biomaterials.2005.07.011.

84. Grohs, J. G.; Gottsauner-Wolf, F. Detection of orthopaedic prostheses at airport security checks. J Bone Joint Surg $\operatorname{Br}$ 1997, 79,385-387, https://doi.org/10.1302/0301-620x.79b3.7604.

85. Al-Tamimi, A. A.; Peach, C.; Fernandes, P. R.; Cseke, A.; Bartolo, P. J. D. S. Topology Optimization to Reduce the Stress Shielding Effect for Orthopedic Applications. Procedia CIRP 2017, 65, 202-206, https://doi.org/10.1016/j.procir.2017.04.032.

86. Pi, Z. P.; Wang, K. L.; Yang, L.; Zhou, Y. C. On the theoretical and phase field modeling of the stress state associated with ferroelastic twin nucleation and propagation near crack tip. Engineering Fracture Mechanics 2020, 235, 107200, https://doi.org/10.1016/j.engfracmech.2020.107200.

87. Bharadwaj, C.; Venkatarayappa, I.; Goswami, T. Stress Shielding in Cemented Hip Implants Assessed from Computed Tomography. Biomedical Journal of Scientific \& Technical Research 2019, 18(3), 13637-13641, https://doi.org/10.26717/BJSTR.2019.18.003163. 
88. https://en.wikipedia.org/wiki/Hip_replacement.

89. Shen , Z.; Crotti , T. N.; McHugh , K. P. The role played by cell-substrate interactions in the pathogenesis of osteoclast-mediated peri-implant osteolysis. Arthritis Res Ther 2006, 8, R70, https://doi.org/10.1186/ar1938.

90. Piao, C.; Wu, D.; Luo, M. et al. Stress shielding effects of two prosthetic groups after total hip joint simulation replacement. J Orthop Surg Res 2014, 9, 71, https://doi.org/10.1186/s13018-014-0071-x.

91. Yao, Z.; Lin, T.H.; Pajarinen, J.; Sato. T.; Goodman, S. Host Response to Orthopedic Implants (Metals and Plastics), Host Response to Biomaterials 2015, 315-373, https://doi.org/10.1016/B978-0-12-8001967.00012-8. 